\title{
INSECT REMOTE SENSING USING A POLARIZATION SENSITIVE CW LIDAR SYSTEM IN CHINESE RICE FIELDS
}

\author{
Shiming Zhu ${ }^{1}$, Elin Malmqvist ${ }^{2}$, Yiyun $\mathrm{Li}^{1}$, Samuel Jansson ${ }^{2}$, Wansha $\mathrm{Li}^{1}$, Zheng Duan ${ }^{1}$, Wei Fu ${ }^{1}$, \\ Katarina Svanberg ${ }^{1,3}$, Joakim Bood ${ }^{2}$, Hongqiang Feng ${ }^{4}$, Susanne Åkesson ${ }^{5}$, Ziwei Song ${ }^{6}$, Baoxin \\ Zhang $^{6}$, Guangyu Zhao ${ }^{1}$, Dunsong Li $^{6}$, Mikkel Brydegaard ${ }^{2,5,7}$ and Sune Svanberg ${ }^{1,3,8^{*}}$ \\ ${ }^{I}$ Center for Optical and Electromagnetic Research, South China Normal University, Guangzhou, China \\ ${ }^{2}$ Combustion Physics Division, Department of Physics, Lund University, Sweden \\ ${ }^{3}$ Lund Laser Centre, Lund University, Sweden \\ ${ }^{4}$ Henan Academy of Agricultural Sciences, Zhengzhou, China \\ ${ }^{5}$ Centre for Animal Movement Research, Department of Biology, Lund University, Sweden \\ ${ }^{6}$ Guangdong Academy of Agricultural Sciences, Guangzhou, China \\ ${ }^{7}$ Norsk Elektro Optikk A/S, Norway \\ ${ }^{8}$ Atomic Physics Division, Department of Physics, Lund University, Sweden \\ *Emailsune.svanberg@fysik.lth.se
}

\begin{abstract}
A joint Chinese-Swedish field campaign of Scheimpflug continuous-wave lidar monitoring of rice-field flying pest insects was pursued in very hot July weather conditions close to Guangzhou, China. The occurrence of insects, birds and bats with almost 200 hours of round-the-clock polarization-sensitive recordings was studied. Wing-beat frequency recordings and depolarization properties were used for target classification. Influence of weather conditions on the flying fauna was also investigated.
\end{abstract}

\section{INTRODUCTION}

Optical monitoring of flying insects is an emerging field of research. There are many reasons for pursuing such endeavors. Certain insects, such as bees are important pollinators, and without their services, many crops would fail. Disease vectors, such as the deadly malaria-spreading mosquito Anopheles, are responsible for annual deaths in the order of one million (especially in Africa), by far outnumbering all armed conflicts, crime and terrorist actions. Finally, agricultural pest insects consume important parts of the crops intended for human consumption. The abatement through the strongly expanding use of pesticides in turn may put human health in jeopardy because of unwanted side effects, and constitutes a huge threat to the pollinators. For these, and additional reasons, effective monitoring of the whereabouts and action of flying insects is of considerable interest. Apart from sampling techniques traditionally pursued by entomologist, short-wavelength radar systems have proven effective in long-range monitoring of flying insects [1,2]. However, such systems cannot record close to the ground, and lack the spectroscopic identification ability, which is available for optical systems. Thus, optical radars, or lidar systems, could be of considerable interest. Pioneering work was pursued by Shaw et al. [3,4], focusing on the detection of hidden mines, found by specially trained honey bees, which aggregate in the air above the explosive, the odor of which is an attracting agent.

The Lund University lidar group started its research activity related to entomology in 2008 . Using a pulsed lidar system, remotely detected fluorescence properties were first studied with mounted static insects, followed by successful field experiments [5]. Chinese agricultural insects were likewise investigated with elastic back-scattering and fluorescence techniques with the Swedish mobile pulsed lidar system brought to Hangzhou, China [6].

Passive, dark-field remote sensing of sunilluminated flying insects observed against a black back-ground is an attractive simple way of recording flying insects. Occurrence, wing-beat frequencies (including overtones), as well as the reflectance spectra of the insects can be assessed [7]. Such work was also pursued by the Guangzhou group with collaborators [8,9]. While attractive, these experiments did not yield range resolution. 


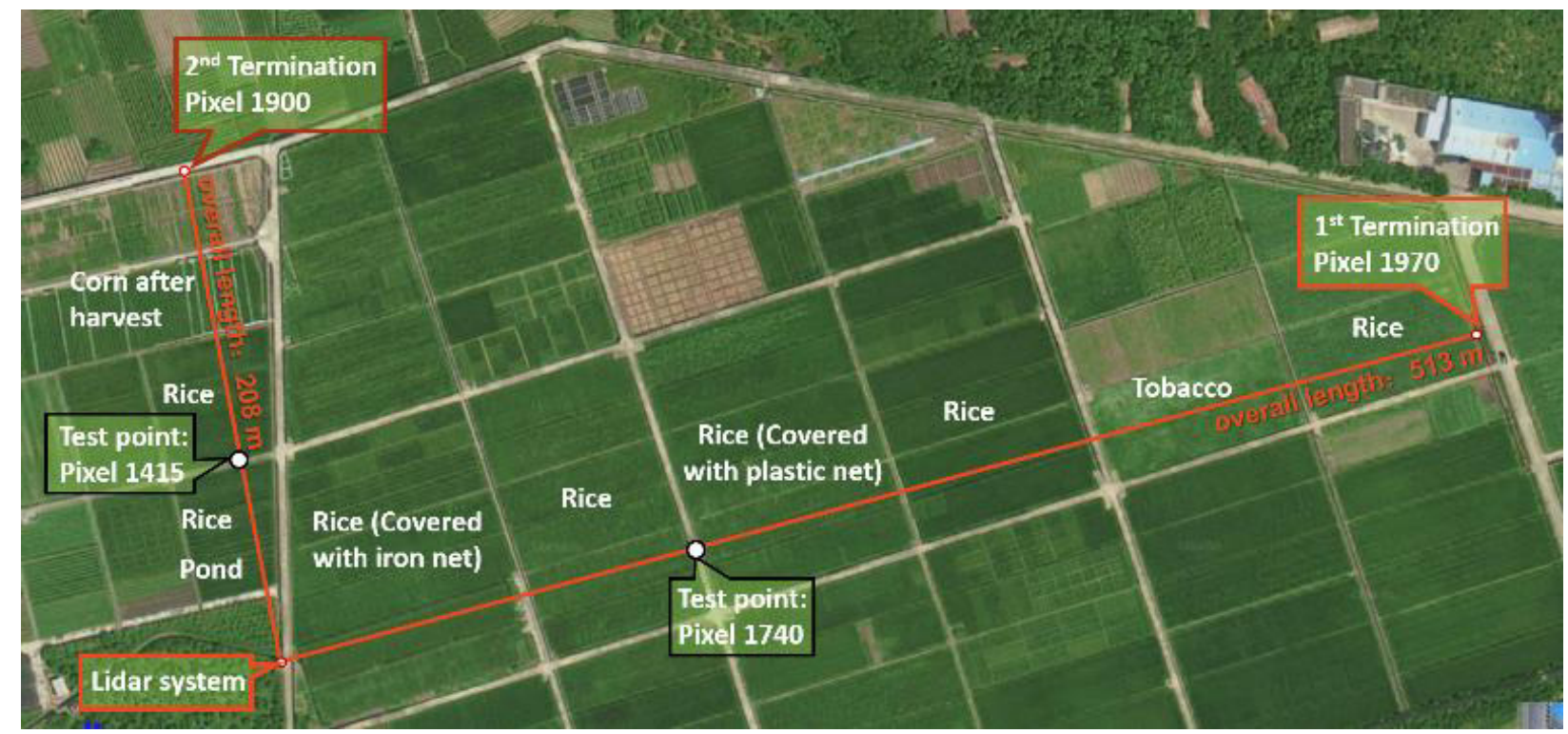

Fig. 1. Field experiment arrangement in Chinese rice fields.

In a simple CW lidar implementation using a socalled Scheimpflug arrangement, range resolution can be achieved $[10,11]$. Basically, a transmitted laser beam is observed by a receiving telescope placed about $82 \mathrm{~cm}$ separated from the transmitting telescope, and the linear array detector observing the back-scattered light is placed in a tilted position, so that close-range, as well as far-range locations can be observed in focus simultaneously. Range-resolution is high at close range while lower at far distance, where ultimately, approaching infinity, all locations fall onto the same detector pixel. On the other hand, and because of this, detected return intensities from air are basically the same for all pixels, in contrast to the customary lidar $1 / \mathrm{R}^{2}$ dependence. Such an arrangement has several attractive features, including reduced cost, weight and complexity, while allowing a high data sampling rate (see, e.g. $[10,11]$ ).

\section{FIELD TEST AND ARRANGEMENTS}

We here report on the arrangement for and results from a joint field experiment campaign pursued in rice fields at an experimental farm belonging to the Guangdong Academy of Agricultural Sciences and located in the Baiyun district north of the major Chinese city of Guangzhou. A CW Scheimpflug lidar set-up arranged for polarization sensitive recordings of flying insects was used. Polarization discrimination provides additional information on the target, e.g. distinction between specular and diffuse reflection, and assessment of, e.g. hair coverage of insects or glossy wings.

The field area with two utilized perpendicular measurement transects is shown in Fig. 1, where also the lengths of the beam paths are indicated. One path regarded crops treated with pesticides while the other, shorter one, represented nontreated conditions. The laser beams were sent at least 2.5 meters above the ground and terminated on large black beam stops. The lidar system and the beam termination are seen in Figs 2a,b. Full security was ensured by constant surveillance of the measurement area. On the order of 200 hours of around-the-clock recordings of insects and, especially in morning and evening hours, birds and bats, were taken during two very hot $\left(24-38^{\circ} \mathrm{C}\right)$ July weeks in Guangdong. We performed extensive monitoring of diurnal variations, the influence of weather, in particular rain-fall, and also studied the insect attraction power of night-time search-light radiation crossing the lidar monitoring beam. An overview figure of the lay-out of the measurement

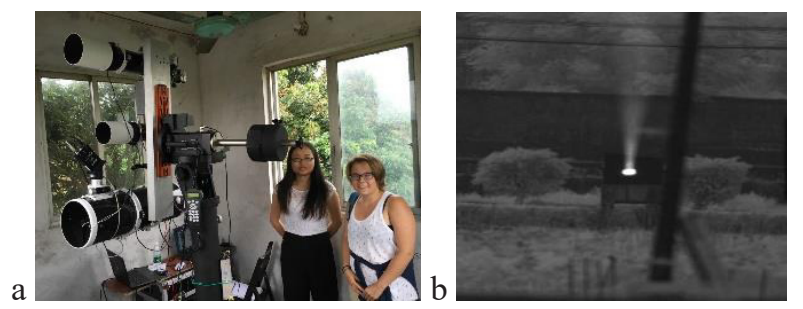

Fig. 2 a) Photograph of the $C W$ lidar measurement system. b) $C W$ laser beam and termination. 


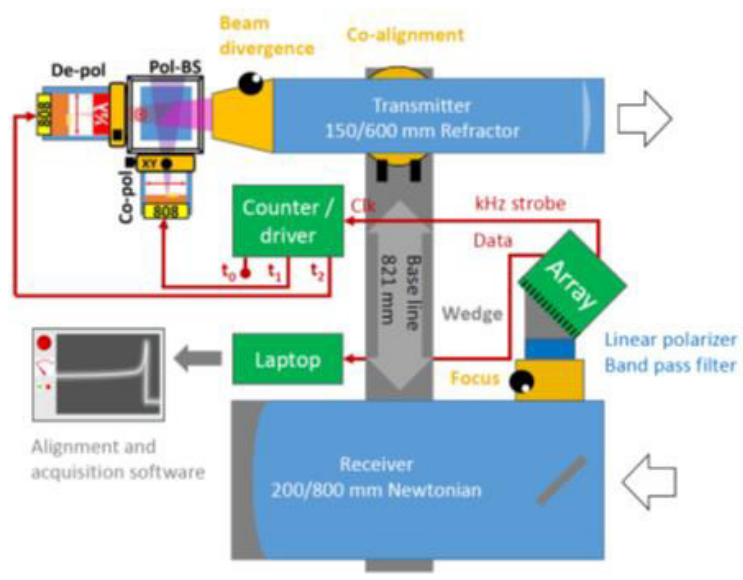

system is given in Fig. 3. The system incorporates two CW lasers operating at $808 \mathrm{~nm}$, and transmitting at perpendicular linear polarizations. The beams are combined and the lasers are activated intermittently with a period of background recording added. A common detector array behind a linear polarizer is utilized. Similar systems, now with two lasers of different wavelengths, have been described - at 405 and 808 $\mathrm{nm}$ [12], and more recently at 980 and $1550 \mathrm{~nm}$ [13], and have been used, e.g. for atmospheric particle characterization.

Fig. 3. Schematic diagram of the $C W$ lidar system.

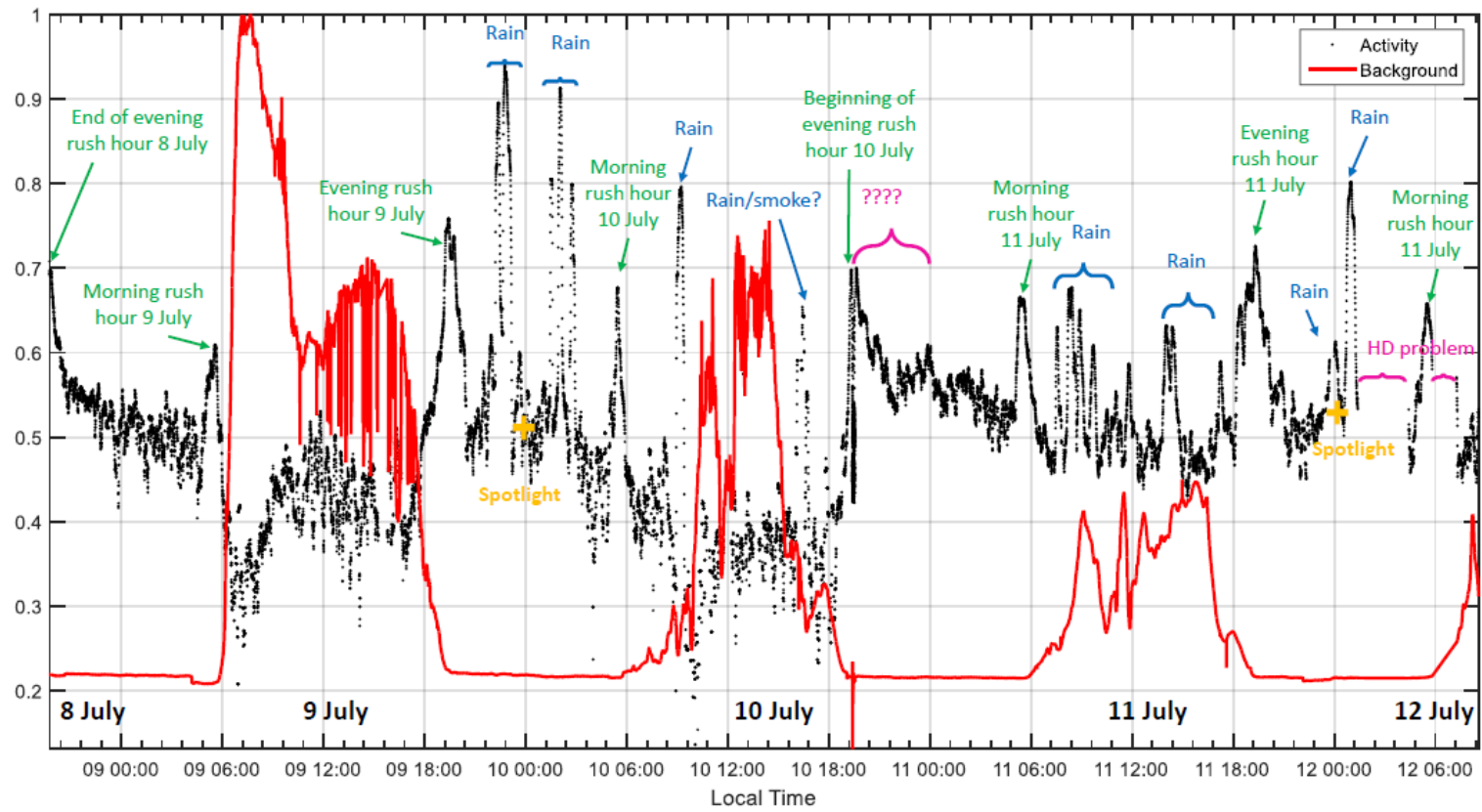

Fig. 4. Data overview for the first four field-experiment days. Atmospheric activity is on logarithmic scale.

\section{MEASUREMENTS AND RESULTS}

Data were recorded continuously as illustrated in Fig. 4, where the number of counts of atmospheric spikes, due to flying fauna as well as rain-drops, is displayed for the longer measuring path together with the signal background light level (the level of day-light). The plot is obtained from system readouts, such as the one in Fig. 5, where individual spikes recorded for both co- and de-polarized light are shown. The strong echo to the far right is due to the beam termination at a range of about $510 \mathrm{~m}$. The signals from high-flying migratory insects, driven down to the ground at the beginning of rain- fall, are shown in Fig. 6. Here, the short passage time of raindrops through the laser beam (less than $8 \mathrm{~ms}$ ) is used to discriminate swiftly falling raindrops from more slowly flying atmospheric fauna.

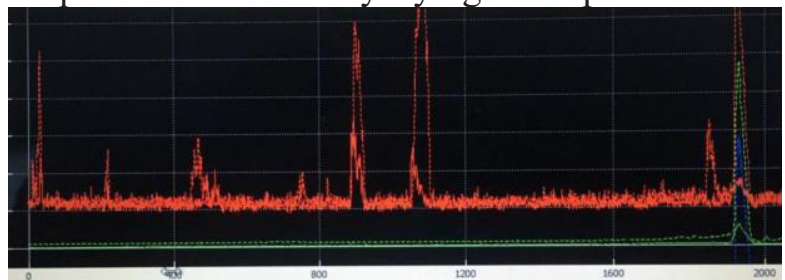

Fig. 5. Computer screen read out showing individual echoes from flying fauna. Beam termination to the right. 


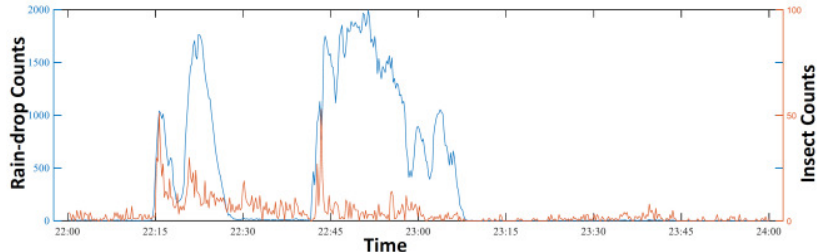

Fig. 6. Insect counts (red) and rain-drop counts (blue) during two night-time hours. High-altitude insects are forced down by the rain-fall.

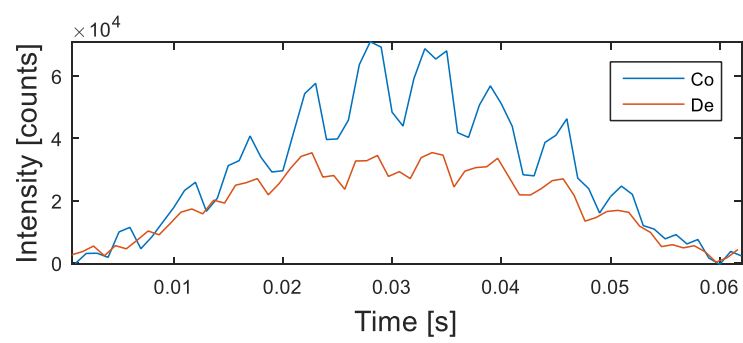

Fig. 7. Passage of an individual insect through the laser beam during $60 \mathrm{~ms}$. Both co- and depolarized signals are displayed. A considerable depolarization suggests that the insect with wingbeat frequency $160 \mathrm{~Hz}$ is not glossy.

For identification of insect species the wing-beat frequency and the depolarization of the backscattered light can be utilized. Each of the hundreds of thousands of insect echo signals can be analyzed in these respects. As an example we show in Fig. 7 the detection of a rice-field insect with a given wing-beat frequency, and displaying a certain depolarization ratio. Clearly, extensive interdisciplinary collaboration between entomologists and the physicists operating the lidar system is needed for proper identification.

\section{References}

1. V.A. Drake, and D.R. Reynolds, Radar Entomology: Observing Insect Flight and Migration (CABI, Wallingford, Oxfordshire, Boston, MA, 2012).

2. J.W Chapman, D.R. Reynolds, A.D. Smith, Vertical-looking radar: A new tool for monitoring high-altitude insect migration. Bioscience 53, 503 (2003).

3. J.A. Shaw, N.L. Seldomridge, D.L. Dunkle, P.W. Nugent, L.H. Spangler, Polarization lidar measurements of honey bees in flight for locating land mines. Opt. Expr. 13, 5853 (2005).
4. E.S. Carlsten, G.R. Wicks, K.S. Repasky, J.L. Carlsten, J.J. Bromenshenk, C.B. Henderson, Field demonstration of a scanning lidar and detection algorithm for spatially mapping honeybees for biological detection of land mines. Appl. Opt. 50, 2112 (2011).

5. Z.G. Guan, M. Brydegaard, P. Lundin, M. Wellenreuther, E. Svensson, S. Svanberg, Insect monitoring with fluorescence LIDAR techniques - Field experiments. Appl. Optics 48, 5668 (2010).

6. L. Mei, Z.G. Guan, H.J. Zhou, J. Lv, Z.R. Zhu, J.A. Cheng, F.J. Chen, C. Löfstedt, S. Svanberg, G. Somesfalean, Agricultural pest monitoring using fluorescence lidar techniques. Applied Physics B 106, 733 (2012).

7. A. Runemark, M. Wellenreuther, H. Jayaweera, S. Svanberg, M. Brydegaard, Rare events in remote dark field spectroscopy: An ecological case study of insects. IEEE JSTQE 18, 1573 (2012).

8. Y.Y. Li, H. Zhang, Z. Duan, M. Lian, G.Y. Zhao, X.H. Sun, J.D. Hu, L.N. Gao, H.Q. Feng, S. Svanberg, Optical characterization of agricultural pest insects: A methodological study in the spectral and time domains, Appl. Physics B, doi 10.10007/s00340-016-6485-x (2016).

9. S.M. Zhu, Y.Y. Li, N.L. Gao, T.Q. Li, G.Y. Zhao, S. Svanberg, C.H. Lu, J.D. Hu, J.R. Huang, H.Q. Feng, Optical remote detection of flying Chinese agricultural pest insects using dark-field reflectance measurements, Acta Sinica Entomologica 59, 1376 (2016).

10. M. Brydegaard, A. Gebru, S. Svanberg, Super resolution laser radar with blinking atmospheric particles - application to interacting flying insects, Prog. Electromagn. Res.147, 141 (2014).

11. M. Brydegaard, Towards quantitative optical cross sections in entomological laser radarPotential of temporal and spherical parameterizations for identifying atmospheric fauna, PLoS One 10, e0135231 (2015).

12. G. Zhao, E. Malmqvist, S. Török, P.-E. Bengtsson, S. Svanberg, J. Bood, et al., Dualband continuous-wave lidar system employed for particle classification, To appear, 2017.

13. M. Brydegaard, J. Larsson, S. Török, E. Malmqvist, S. Jansson, M. Andersson, S. Svanberg, S. Åkesson, F. Laurell, J. Bood,' Shortwave Infrared Atmospheric Scheimpflug lidar, ILRC28. 